\title{
RNF43 NP_060233.3:p.D140E
}

National Cancer Institute

\section{Source}

National Cancer Institute. RNF43 NP 060233.3:p.D140E. NCI Thesaurus. Code C146975.

A change in the amino acid residue at position 140 in the E3 ubiquitin-protein ligase

RNF43 protein where aspartic acid has been replaced by g lutamic acid. 